\title{
Atividades Cotidianas de Crianças em Situação de Rua ${ }^{1}$
}

\author{
Paola Biasoli Alves² \\ Universidade Católica de Brasília \\ Sílvia Helena Koller, Aline Santos Silva, Clarisse Longo do Santos, \\ Milena Rosa da Silva, Caroline Tozzi Reppold e Luciano Telles Prade \\ Universidade Federal do Rio Grande do Sul
}

\begin{abstract}
RESUMO: Este estudo apresenta resultados de uma pesquisa descritiva da observação de atividades cotidianas de vinte crianças em situação de rua da área central de Porto Alegre, Brasil. Os dados foram coletados através de uma metodologia observacional elaborada especificamente para utilização em pesquisas no contexto da rua, associada a uma entrevista estruturada para obtenção de dados bio-sócio-demográficos. Os resultados revelam que as crianças utilizam o espaço da rua para diversas atividades, incluindo tarefas que garantem a subsistência pessoal e, às vezes, da família. Foram também observadas brincadeiras solitárias ou em grupo, demonstrando que embora estejam em atividade de trabalho, continuam sendo crianças em desenvolvimento. A discussão dos dados, baseada na Teoria dos Sistemas Ecológicos, salienta a importância de estudos que descrevam os aspectos saudáveis que meninos e meninas em situação de rua podem apresentar neste ambiente. Alternativas de intervenção nesta situação devem enfatizar a participação comunitária e da sociedade civil na efetivação de propostas de apoio sócio-afetivo para estas crianças e suas famílias.
\end{abstract}

Palavras-chave: crianças de rua; trabalho infantil; brinquedo; família; espaço da rua.

\section{Daily Activities of Street Children}

\begin{abstract}
This descriptive study shows the daily activities of twenty street children of Porto Alegre central area, Brazil. Observational methodology and a structured interview were elaborated for this research. The results revealed that children use the streets for diverse activities, including those that guarantee their personal surveillance and their families subsistence. Some solitary play was observed, demonstrating that even when working, those children keep developing characteristics. The data has been discussed based on the Ecological System Theory, pointing out the importance of studies that describe healthy aspects in that environment. Intervention may emphasize the community and the civil society participation to support those children and their families.
\end{abstract}

Key words: street children; children's work; play; family; street.

O estudo de aspectos evolutivos de crianças e adolescentes que vivem em situação de risco pessoal e social, dentro das Ciências Humanas e da Saúde, vem crescendo a cada ano (Alves, 1998; Cecconello, 1999; Garmezy \& Masten, 1994; Mayer, 1998; LaCharrité, 1998; Rutter, 1993). Situação de risco, para crianças que vivem ou trabalham na rua, significa sofrer a miséria econômica e/ou afetiva e suas inúmeras conseqüências. Pesquisadores na área do Desenvolvimento vêm realizando estudos embasados em um modelo de valorização dos aspectos saudáveis do ciclo vital, sugerindo processos de intervenção e prevenção a situações de risco contextualizado (Cecconello, 1999; Hutz \& Koller, 1997; LaCharrité, 1998).

1 Este trabalho é parte da Dissertação de Mestrado da primeira autora, sob orientação da segunda autora, no Programa de Pós-Graduação em Psicologia do Desenvolvimento da Universidade Federal do Rio Grande do Sul, Porto Alegre, RS. Os autores agradecem a colaboração do Prof. Jonathan Tudge durante a elaboração das primeiras versões deste texto. Apoio CAPES.

2 Endereço: CSB 08, lote 03/ 04, ED. Rio de Janeiro, 327, Taguatinga Sul, DF, CEP: 72015-585. E-mail: pbiasoli@ucb.br
Dentro do quadro geral das diferentes situações de risco, as crianças que se desenvolvem em situação de rua compõem um grupo com características especiais. Elas têm sido definidas como crianças que passam ao menos um período do seu dia nas ruas, sozinhas ou em grupos, apresentam aparência de abandono, com visível falta de higiene e realizando tarefas humildes, visando à sua subsistência e à de sua família. Na maioria das vezes, não é possível identificar um adulto cuidador nas proximidades onde atuam, reforçando a aparente autonomia e independência demonstrada pelas crianças dentro da situação vivida (Alves, 1998; Forster, Barros, Tannhauser \& Tannhauser, 1992). Esta definição apenas caracteriza os aspectos relacionados ao contexto da rua, mas não oferece outras especificidades sobre estas crianças. É fundamental respeitar seus processos individuais de desenvolvimento, que variam de acordo com suas histórias de vida e suas habilidades particulares para definir cada uma delas, enquanto pessoa em desenvolvimento (Alves, 1998). Esta visão mais ampla é discutida por Hutz e Koller (1997), que analisam aspectos do desenvolvimento social, cognitivo, físico e emocional.

O desenvolvimento social assume características particulares para crianças cujo ambiente principal de socializa- 
ção é a rua. Sobreviver nesse ambiente implica a criação e o exercício de estratégias variadas, que auxiliem na obtenção de alimento e abrigo, possibilitando sua sobrevivência e segurança. Nesse sentido, estudos têm demonstrado a capacidade de crianças em situação de rua em aproveitar as experiências de afeto e proteção vivenciadas dentro de seus grupos (Hutz \& Koller, 1997; Kuschick, Reppold, Dani, Raffaelli \& Koller, 1996). O senso de pertencimento a grupos específicos e a identidade social recebida por estas interações funciona como fator de proteção à agressão advinda da exclusão e marginalização imposta pela vida na rua (Hutz \& Koller, 1997; Koller, 1994; Kuschick \& cols., 1996).

O desenvolvimento cognitivo destas crianças deve ser compreendido, também, de forma contextualizada. As experiências na rua permitem o exercício de diversas habilidades e formas de raciocínio, que não são, necessariamente, congruentes com as mensuradas em estudos formais sobre cognição (Carraher, Carraher \& Schliemann, 1985). Algumas funções podem ser diretamente afetadas pelo uso contínuo e abusivo de drogas, prática presente na vida de algumas dessas crianças (Forster \& cols., 1992; Hutz \& Koller, 1997).

O estudo do desenvolvimento emocional de crianças que saem de suas casas e, muitas vezes, preferem viver na rua, tem sido um desafio para os estudiosos da área. Os relatos frequientes de experiências abusivas na família se contrapõem aos dados que explicitam os riscos da vida na rua aos quais estão submetidas estas crianças. No entanto, além de manter-se na rua, estas crianças revelaram, em alguns estudos, mais saúde emocional do que seus irmãos que permaneceram junto à família de origem (Aptekar, 1989; Kuschick \& cols., 1996; Peres, 1997).

O desenvolvimento físico, de uma certa forma, legitima o espaço da rua como espaço provedor de subsistência. A alimentação obtida na rua e nas instituições de atendimento às populações de rua pode ser, muitas vezes, mais variada e nutritiva do que a disponível (quando disponível) nas casas de onde saíram. No entanto, embora haja alguma evidência quanto à disponibilidade nutricional, a exposição ao risco na realidade da rua, inclui a violência, os acidentes, o risco de contágio de doenças e a ausência de abrigos como problemas para a preservação física destas crianças (Hutz \& Koller, 1997).

A pesquisa com crianças em situação de rua requer cuidados especiais dos pesquisadores, com questões éticas e metodológicas, relacionadas à conceituação da rua como espaço de desenvolvimento. Bemak (1996) aponta para a necessidade de o pesquisador adaptar-se ao contexto da rua, que tem cultura e valores próprios, identificando e aprendendo a dinâmica desse espaço que abriga trabalho, lazer, alimentação e diversão, comporta diferentes faixas etárias e diversos níveis de contatos e interações sociais. A rua oferece inúmeras possibilidades de diversão, seja em praças e parques, casa de jogos eletrônicos ou através da apreciação do movimento constante de pessoas e de pequenos shows promovidos por ambulantes e trabalhadores independentes. Connoly e Ennew (1996) revelam que a rua oferece, também, meios de subsistência para as crianças, através do exer- cício de tarefas pequenas e humildes, uma vez que sua idade impossibilita uma inserção legal no mercado de trabalho. Esta visão de utilização do espaço da rua aparece também em estudos brasileiros na área do Serviço Social, Psicologia e Educação, que listam uma série de atividades diárias executadas por crianças no espaço da rua, tais como, vagar pela rua, brincar, trabalhar (lavar carros, cuidar carros, vender pequenos objetos, engraxar sapatos, esmolar, etc.), usar drogas, roubar, dormir e prostituir-se (Bandeira, Koller, Hutz \& Forster, 1994; Koller, 1994; Kuschick \& cols., 1996; Reppold, Santos, Silva, Silva, Alves \& Koller, 1996b; Zeebell, Garcia \& Silveira, 1995).

Aptekar (1994) considera a vivência de rua como um conjunto de aspectos importantes na discussão de metodologias de pesquisa com esta população. $\mathrm{O}$ dia a dia na rua desenvolve a chamada sabedoria de rua, que envolve a aprendizagem da sobrevivência neste espaço, pela aquisição e utilização de repertórios comportamentais específicos para cada situação e contato social. Muitas vezes, as crianças adequam suas histórias ao que imaginam que os ouvintes estão esperando, sejam estes instituições, policiais, transeuntes ou pesquisadores. Por outro lado, a imagem que o pesquisador tem das crianças poderá determinar sua atitude durante o procedimento de abordagem e coleta de dados. Esta imagem varia entre dois extremos: da criança vítima e passiva ao da criança heroína e esperta, que sobrevive em um mundo hostil, sem regras ou adultos responsáveis. Estas duas visões extremadas dificultam seriamente o estabelecimento de um vínculo e de planos de ação que visem à execução da pesquisa e de intervenções posteriores (Aptekar, 1989, 1994).

Outro aspecto do desenvolvimento destas crianças no ambiente da rua, enfatizado pela literatura refere-se à atenção flutuante estimulada pela variedade de estímulos presentes, o exercício de atividades de trabalho, o cuidado com a exposição demasiada e a desconfiança constante (Koller, 1994). Estes fatores devem direcionar a busca de instrumentos de coleta de dados, que possam ser utilizados, de forma a abranger o máximo de variáveis e que respeitem as particularidades da atenção da criança, sem prejudicar o potencial descritivo e o significado destes dados.

Permeando esta discussão metodológica, existem questões éticas envolvendo o processo de coleta dos dados e a publicação de resultados das pesquisas com crianças em situação de rua. Autores discutem a necessidade de se garantir a estas crianças sigilo e proteção, assim como respeitar seu desejo de participar ou não da pesquisa, frente à apresentação clara dos objetivos e procedimentos da mesma. Na ausência de um adulto responsável (mesmo que esta seja uma condição momentânea), a criança deve ser considerada como responsável por si mesma e capaz de tomar decisões. Cabe ao pesquisador respeitar seus direitos e evitar a exposição a situações que potencializem riscos (Hutz \& Koller, 1999).

A Teoria dos Sistemas Ecológicos proposta por Bronfenbrenner (1979/1996, 1989, 1993, 1995; Bronfenbrenner \& Morris, 1998), vem sendo considerada como uma base adequada, tanto teórica como metodologicamente, para o estudo de crianças em situação de rua e de seu desenvolvimento 
(Alves, 1998). Esta teoria permite a construção de uma abordagem saudável e contextualizada do desenvolvimento (em oposição àquelas baseadas no estudo de aspectos psicopatológicos), procurando enfocar, dinamicamente, a pessoa e suas particularidades e o ambiente no qual está inserida. Há o privilegio de estudos em ambientes naturais como meio de obtenção de dados relevantes, o mais próximo possível da realidade cotidiana vivenciada pelos informantes (Alves, 1998, 1999).

A Teoria dos Sistemas Ecológicos considera quatro núcleos básicos, que interagem entre si, dinamicamente: Pessoa, Contexto, Processo e Tempo. Para Bronfenbrenner e Morris (1998, p. 995), o desenvolvimento humano é definido como a "estabilidade e mudança nas características biopsicológicas dos seres humanos através do ciclo vital e entre gerações". A amplitude desta colocação pode ser mais bem compreendida se os quatro núcleos citados forem definidos em separado.

Segundo Bronfenbrenner e Morris (1998), a Pessoa deve ser entendida levando-se em conta: a) demanda: estímulos pessoais, características próprias e particulares das pessoas (determinadas tanto por aspectos psicológicos como biológicos), que atuam diretamente sobre o ambiente e favorecem ou não sua adaptação e crescimento; b) disposição: características pessoais, que na interação com o ambiente, encorajam ou não a existência e manutenção de relações saudáveis. Essas características, quando em atuação, exigem do ambiente uma resposta, ou seja, dispõem o ambiente para a interação; c) recursos: características bioecológicas (atuantes na interação pessoa-ambiente) que representam habilidades, experiências e conhecimento requeridos para o desenvolvimento saudável.

A vida da rua constitui-se em um ambiente privilegiado para o estudo do desenvolvimento de crianças, exigindo que o pesquisador esteja atento para características individuais, evitando generalizações quanto aos comportamentos apresentados e desvalorizações de aspectos como etnia, gênero, competência social, auto-eficácia e redes de apoio sócioafetivas. Estudos das características pessoais podem gerar compreensão sobre os mecanismos de resiliência e/ou vulnerabilidade destas crianças, fatores intimamente ligados a um desenvolvimento saudável (Alves, 1998).

O Processo, descrito por Bronfenbrenner (1989), diz respeito aos aspectos psicológicos da pessoa em desenvolvimento, intrinsecamente relacionados com a forma como vê e interpreta seu momento de vida e seu ambiente, identificando a importância dos diversos aspectos presentes e a relação que faz entre eles. A análise sistemática das atividades realizadas cotidianamente por estas crianças, a identificação de seus pares de ação e o sentido atribuído para cada evento descrevem a dinâmica do processo proximal de desenvolvimento. Esse processo é considerado por Bronfenbrenner e Morris (1998) como o mais relevante a ser estudado, pois permite a compreensão exata do desenvolvimento enquanto um processo de interação, no qual cada atividade realizada tem o potencial de manter e aprofundar relações de afeto, reciprocidade e equilíbrio de poder (Alves, 1997, 1998).
No caso do estudo de crianças em situação de rua, estar atento para as características da Pessoa e para os aspectos envolvidos no Processo significa valorizar cada criança em particular, buscando conhecer sua opinião e posicionamento frente à sua realidade, e sua atuação no ambiente. Em pesquisas pode-se utilizar, além da observação direta, uma entrevista que permita que a criança fale sobre si mesma, como sugerido por Reppold, Santos, Silva, Silva, Alves e Koller (1996a). As opiniões e expressões das crianças são veículos viáveis e fidedignos para a criação e/ou implementação de serviços que procurem alternativas para sua situação, devendo ser complementados com outros instrumentos, como a observação. Nunes (1994) salienta que, em trabalhos com instituições que atendem crianças em situação de risco, é necessário que sejam investigadas crenças e expectativas com relação à população atendida. A voz ativa das crianças neste processo possibilita maior preparação dos profissionais para lidar com a realidade cotidiana delas, efetivando políticas adequadas de assistência.

Com relação ao núcleo Contexto, Bronfenbrenner (1979/ 1996, 1989, 1993) descreve quatro sistemas de análise:

a) microssistema: definido pela dimensão que possibilita a interação face-a-face entre a pessoa em desenvolvimento focalizada, os outros (também em desenvolvimento), símbolos e objetos. Refere-se ao espaço de interação de diferentes personalidades, que convivem com diversos valores e crenças. A rua pode ser definida como um microssistema no contexto de desenvolvimento das crianças em situação de rua.

b) mesossistema: definido como a interligação de diversos microssistemas aos quais pertence a pessoa em desenvolvimento, estabelecendo relações face-a-face com outras pessoas. Os microssistemas rua, família, escola, grupos comunitários e de assistência podem integrar o mesossistema das crianças em situação de rua.

c) exossistema: definido como espaço de interação e convivência, no qual a pessoa em desenvolvimento focalizada não se encontra presente, mas do qual sofre influência direta da dinâmica de suas interações. Pode ser representado, neste estudo, pelas coordenações de instituições de assistência social e recreativa, grupos que tomam decisões quanto a políticas públicas, trânsito, planejamento de atividades nas ruas, praças, entre outros e;

d) macrossistema: definido como a totalidade dos sistemas anteriores, que representam a cultura na qual está inserida a pessoa em desenvolvimento focalizada, o conjunto de crenças e valores, as regras e papéis esperados e difundidos dentro deste contexto mais amplo, além dos aspectos econômicos, sociais e históricos. No estudo de crianças em situação de rua, é relevante o conhecimento sobre o desenvolvimento econômico da cidade no qual se insere, como a sociedade vê a problemática das crianças, o preconceito vigente e os fatos marcantes que possam ter ocorrido num espaço de tempo determinado e influenciado a vida destas crianças.

Diretamente relacionado aos sistemas que compõem o núcleo Contexto do desenvolvimento, Bronfenbrenner 
(1989) apresenta o núcleo Tempo, que denomina cronossistema, e reputa como de suma importância e influência sobre o processo de desenvolvimento, abrangendo desde grandes acontecimentos históricos (a Copa do Mundo e o Plano Real, por exemplo) até pequenos episódios da vida cotidiana que se processam continuamente (saída de casa, institucionalização, entrada em algum projeto de trabalho, etc.; Bronfenbrenner \& Morris, 1998). É fundamental, para o pesquisador, conhecer os momentos da vida em que existiram episódios significativos para as crianças, para uma possível compreensão de sua influência no seu processo de desenvolvimento. Os núcleos Contexto e Tempo podem ser captados pela observação do pesquisador na situação de rua, mas precisam de dados obtidos por meio de entrevista, que abordem de forma flexível e complementar, tópicos relativos à história da criança, valorizando a apreensão contextualizada dos dados.

Outra proposição importante da Teoria Ecológica a ser considerada refere-se ao conceito de atividades molares, definidas como "um comportamento continuado que possui um momento (quantidade de movimento, impulso) próprio e é percebido como tendo significado ou intenção pelos participantes" (Bronfenbrenner, 1979/1996, p.37). A identificação e o acompanhamento de atividades molares permite uma visão dinâmica da interação da pessoa em desenvolvimento com o seu ambiente. A realização das atividades molares vincula-se com o crescimento psicológico e social dos seres humanos e está presente como característica do processo proximal. A atuação nestas atividades demanda atenção, dispêndio de energia e exercício de habilidades, com um objetivo a ser alcançado. E o desenvolvimento permite que sejam realizadas com crescente autonomia, às vezes, mais de uma ao mesmo tempo, relacionando-se com o desempenho de diferentes papéis. Este processo é importante para que a criança reconheça e apreenda as regras do ambiente, atuando diretamente neste contexto.

As atividades molares podem ser codificadas e contabilizadas, favorecendo a compreensão dos dados e o estabelecimento de parâmetros de interpretação. Esta é uma das unidades de análise deste estudo, norteando a criação e utilização do Manual de Codificação de Atividades Cotidianas de Crianças em Situação de Rua (Alves, Koller \& Tudge, 1996; Alves, Silva, Reppold, Santos, Bichinho, Prade, Silva, Koller \& Tudge, 1999).

Considerando estes aspectos teóricos e metodológicos, é apresentada a seguir a descrição deste estudo, realizado com vinte crianças em situação de rua, do centro de Porto Alegre, objetivando compor um quadro descritivo de suas atividades cotidianas.

\section{Método}

Este é um estudo descritivo sobre as atividades cotidianas de crianças em situação de rua do centro de Porto Alegre. Foram investigadas as atividades que realizam no espaço da rua, através de um método de observação em ambiente natural, especialmente desenvolvido para o estudo de crianças em situação de rua (Alves \& cols., 1999) e orientado pelos pressupostos da Teoria Ecológica.

\section{Participantes}

Vinte (20) crianças em situação de rua do centro de Porto Alegre, com idade entre seis e doze anos, identificadas como tal, segundo a caracterização proposta por Forster e colaboradores (1992) e ampliada pelos autores, constituíram a amostra. Tal caracterização inclui aparência de abandono (identificável pela qualidade e limpeza das vestimentas, a inadequação entre o tamanho da criança e das roupas e sapatos utilizados), o exercício de tarefas humildes (venda de pequenos objetos - lixas de unha, santinhos, flores; cuidado de carros, abertura de portas de táxi para passageiros, mendicância) e a ausência de um adulto cuidador imediatamente identificável na situação de rua. A Tabela 1 apresenta uma breve descrição da amostra, com dados bio-sóciodemográficos.

\section{Instrumentos}

\section{Observação em Ambiente Natural com Registro Cursivo}

Este método foi utilizado para identificar as atividades realizadas pelas crianças no ambiente da rua, seus comportamentos e pares de contato social. Os registros foram realizados durante trinta (30) minutos consecutivos e, posteriormente, codificados de acordo com o Manual de Codificação de Atividades de Crianças em Situação de Rua (Alves, Koller \& Tudge, 1996; Alves \& cols., 1999). Este manual foi baseado no original proposto por Tudge, Sidden e Putnam (1994). Os dados obtidos através deste instrumento permitem a descrição de aspectos do microssistema da rua, incluindo as atividades molares e moleculares realizadas e, basicamente, a ocorrência de processos proximais de desenvolvimento.

\section{Entrevista Estruturada}

A entrevista teve como objetivo coletar dados bio-sóciodemográficos, tais como: idade, composição familiar, experiências com trabalho e escola, atividades que realizam du-

Tabela 1. Caracterização da Amostra por Sexo, Média de Idade, Freqüência na Escola, Trabalho, Moradia e Contato com a Família

\begin{tabular}{|c|c|c|c|c|c|c|c|c|c|c|}
\hline & $\begin{array}{c}\mathrm{N}^{0} \text { de } \\
\text { Participantes } \\
\end{array}$ & $\begin{array}{l}\text { Idade } \\
\text { média }\end{array}$ & Estuda & $\begin{array}{c}\text { Não } \\
\text { Estuda }\end{array}$ & Trabalha & $\begin{array}{c}\text { Não } \\
\text { Trabalha } \\
\end{array}$ & $\begin{array}{c}\text { Mora na } \\
\text { rua }\end{array}$ & $\begin{array}{c}\text { Mora em } \\
\text { casa }\end{array}$ & $\begin{array}{c}\text { Tem contato diário } \\
\text { com a família }\end{array}$ & $\begin{array}{c}\text { Não tem contato } \\
\text { com a família }\end{array}$ \\
\hline Meninos & 12 & $10 \mathrm{a}$. & 07 & 05 & 10 & 02 & 05 & 07 & 10 & 02 \\
\hline Meninas & 08 & $10 \mathrm{a}$. & 04 & 04 & 08 & - & - & 08 & 08 & - \\
\hline Total & 20 & & 11 & 09 & 18 & 02 & 05 & 15 & 18 & 02 \\
\hline
\end{tabular}


rante o dia e a noite, trabalho dos pais ou responsáveis e sua preferência entre brincar e trabalhar.

\section{Procedimentos de Coleta de Dados}

Para a realização deste estudo, foram observados os refinamentos metodológicos sugeridos na pesquisa com crianças em situação de rua (Reppold \& cols., 1996a, 1996b; Alves $\&$ cols., 1999). Dois procedimentos básicos com relação à observação de crianças em situação de rua foram adotados: a) O tempo ideal de observação destas crianças em ambiente natural (a rua) foi estabelecido em trinta minutos, considerando características das crianças, do ambiente observado e dos observadores;

b) A presença de uma dupla de observadores durante a coleta de dados foi adotada, favorecendo a qualidade do registro dos dados e do acompanhamento da criança.

Reppold e colaboradores (1996a, 1996b) ressaltam que a autorização da criança para a utilização dos dados é essencial. Contudo, o momento de solicitação da anuência (antes ou após a observação) deve ser adequado ao objetivo do estudo. Em estudos que objetivem a descrição de atividades cotidianas, ou de atividades específicas (brinquedo e trabalho, por exemplo), é necessário que esta solicitação seja feita após o período de observação. Este procedimento permite o registro de comportamentos naturais e não estereotipados, freqüentes quando os participantes estão a par dos objetivos da pesquisa.

Neste estudo, a coleta de dados foi realizada seguindose os seguintes passos:

a) Foi escolhido um starting point (ponto inicial) geográfico para o início das observações, comportando tanto o trabalho como a diversão das crianças. O local escolhido foi uma quadra da rua dos Andradas, no centro da cidade de Porto Alegre. Os pesquisadores, presentes neste local entre $10 \mathrm{hs}$ e $15 \mathrm{hs}^{3}$, inicialmente, identificavam uma criança em situação de rua, com idade estimada entre seis e doze anos, e iniciavam o processo de observação. A criança era acompanhada por trinta minutos, a uma distância de dez a cinqüenta metros, tendo todos seus comportamentos registrados continuamente. Para se evitar a observação de uma mesma criança repetidamente, um mesmo pesquisador participou das identificações, antes do início de cada observação.

b) Após o período de observação, os pesquisadores aproximavam-se da criança ${ }^{4}$, apresentavam-se, falavam sobre o trabalho e pediam permissão para utilizar os dados. Frente à anuência da criança, ela era convidada a responder à entrevista. Foi solicitada a permissão da cri-

3 Este horário foi estabelecido após algumas observações piloto, sendo considerado como o período mais adequado devido a maior presença das crianças neste horário (Reppold \& cols., 1996a, 1996b).

4 Os seis pesquisadores que participaram deste estudo foram capacitados pelo Centro de Estudos Psicológicos sobre Meninos e Meninas de rua (CEP-RUA) para abordagem de crianças em situação de rua. ança para a utilização de um gravador, instrumento que facilitou o registro dos dados e sua posterior análise.

\section{Resultados}

Estudos descritivos envolvem a categorização e a quantificação dos dados. A entrevista foi analisada através do levantamento de frequiências das respostas. Para a análise dos dados de observação e das sentenças, adotou-se o modelo quantitativo-interpretativo proposto por Biasoli-Alves (1988), descrito a seguir:

a) Investigação: Investiga-se cada comportamento ou resposta apresentada, classificando-os segundo a proximidade de sentido que apresentam. Nesta etapa, objetivase compreender o significado e a importância do dado coletado para os objetivos do estudo, além de analisar a relevância e adequação do instrumento utilizado, frente aos resultados obtidos.

b) Categorização: Através de um estudo minucioso de cada comportamento ou fala dos participantes, cria-se agrupamentos válidos dos dados. Os critérios utilizados para a criação destes agrupamentos (categorias) são: exaustividade (análise de todas as formas de respostas obtidas), exclusividade (cada categoria classifica um grupo de respostas) e manutenção (as categorias devem ter um mesmo nível de inferência e interpretação das respostas, evitando-se grandes oscilações no contínuo objetividade-subjetividade).

Os registros das observações foram exaustivamente examinados pelo grupo de pesquisa e, a partir de sua leitura, organizou-se uma primeira versão do Manual de Codificação de Atividades de Crianças em Situação de Rua (Alves, Koller \& Tudge, 1996). A versão final desse material e todo seu processo de construção aparecem em artigo específico sobre metodologia (Alves \& cols., 1999).

A codificação das observações ordenou os dados da seguinte maneira: a) papel desempenhado pela criança na atividade; b) pessoas com as quais as crianças tiveram contato durante as observações; e, c) atividades observadas.

O papel desempenhado pelas crianças nas atividades foi categorizado como: direção (a criança tinha o comando da atividade), participação (a criança participava da atividade em conjunto com seus pares e dividia a direção da tarefa), espreita (a criança observava, sem ser notada, uma atividade realizada por outrem), observação (a criança observava a realização de alguma atividade e sua presença era notada), conflito (a criança participava de alguma atividade onde havia conflito com o par) e esquiva (a criança evitava envolver-se na atividade). $\mathrm{O}$ desempenho destes papéis esteve presente em $100 \%, 95 \%, 65 \%, 25 \%, 25 \%$ e $25 \%$ das atividades observadas, respectivamente.

Os pares de contato social das crianças durante as atividades observadas variaram de acordo com a idade e o gênero (masculino e feminino). Para definir as faixas etárias das pessoas com as quais as crianças mantiveram contato, foram consideradas adultas, aquelas pessoas com aparência de idade superior a dezoito anos; adolescentes, aquelas com 
idade estimada entre doze e dezoito anos; e, crianças, os pares com idades estimada entre zero e doze anos. Foi anotada a presença de um ou mais contatos sociais na mesma interação. Pares puderam ser classificados tanto isoladamente ou em grupo, dependendo da situação. Os resultados revelaram que os contatos mais frequientes das crianças em situação de rua observadas são realizados com adultos do sexo masculino, seguidos de adultos do sexo femininos e outras crianças do sexo masculino. Grupos de adultos e de crianças foram os contatos menos freqüentes.

Foi observado um total de 2724 atividades, categorizadas como: brinquedos, brincadeiras e exploração do ambiente $(25,33 \%)$, contatos sociais $(11,43 \%)$, observação do contexto $(10,5 \%)$, trabalho $(3,37 \%)$ e outras $(49,45 \%)$. Neste artigo serão descritas em maior detalhe as três categorias mais freqüentes: outras (incluem atividades motoras, compra e consumo de comida), brinquedo e observação do contexto. $\mathrm{O}$ trabalho foi uma atividade pouco freqüente e será discutido em conjunto com os outros dados. A Tabela 2 traz os dados relativos à categoria Outras, a mais freqüentemente observada.

Tabela 2. Freqüência de crianças que apresentaram atividades motoras, de compra e de consumo de alimentos, percentagem do total da amostra e média de ocorrência da atividade por criança $(n=20)$

\begin{tabular}{lccc}
\hline \multicolumn{1}{c}{ Atividades } & Freqüiência & $\begin{array}{c}\text { Média por } \\
\text { criança }\end{array}$ & Percentagem \\
\hline Atividade motora ampla & 20 & 32,45 & 100 \\
Atividade motora restrita & 20 & 24,95 & 100 \\
Comer & 14 & 5,92 & 70 \\
Estar parado & 13 & 1,69 & 65 \\
Comprar algo & 4 & 1,75 & 20 \\
\hline
\end{tabular}

A atividade motora ampla (correr, andar, sentar, etc.) e a motora restrita (coçar, passar a mão no cabelo, etc.) foram as mais freqüentemente observadas (comportamentos presentes em $100 \%$ da amostra). A alta frequiência dos comportamentos motores indica a mobilidade das crianças no espaço da rua e a utilização de seu próprio corpo nesta tarefa. Também, o comer aparece como uma atividade constante destas crianças, revelando o contexto da rua como capaz de prover a subsistência diária, em termos de disponibilidade de alimentação, para estas crianças. Não está considerada aqui a qualidade nutricional destes alimentos. A Tabela 3 apresenta os dados da observação das atividades de brinquedo, a segunda categoria mais freqüente neste estudo.

A Tabela 3 mostra que as crianças observadas utilizamse, principalmente, do seu próprio corpo e dos objetos que têm à sua disposição, no espaço da rua, para brincar. Em algum momento das observações, cada uma das crianças expressou, ao menos uma vez, estas duas atividades. A brincadeira com objetos do mundo adulto (pneus, dinheiro) e com a própria roupa também foram freqüentes, mostrando, mais uma vez, a utilização do que se encontra presente no contexto para brincar. A Tabela 4 mostra as dados das atividades de observação do contexto, a terceira categoria mais observada.
Tabela 3. Freqüência de crianças que apresentaram atividades de brinquedo, percentagem do total da amostra e média de ocorrência da atividade por criança $(n=20)$

\begin{tabular}{|c|c|c|c|}
\hline Brinquedo & Freqüência & Média & Percentagem \\
\hline Brinquedo com o próprio corpo & 20 & 11,15 & 100 \\
\hline $\begin{array}{l}\text { Brinquedo com objeto presente no } \\
\text { contexto }\end{array}$ & 20 & 8,70 & 100 \\
\hline $\begin{array}{l}\text { Brinquedo com objeto do mundo } \\
\text { adulto }\end{array}$ & 11 & 6,09 & 55 \\
\hline Brinquedo com vestimenta & 10 & 3,20 & 50 \\
\hline $\begin{array}{l}\text { Brinquedo orientado para o } \\
\text { mundo infantil }\end{array}$ & 7 & 14,14 & 35 \\
\hline $\begin{array}{l}\text { Brinquedo de faz-de-conta } \\
\text { genérico }\end{array}$ & 6 & 1,80 & 30 \\
\hline Brinquedo com objeto de trabalho & 5 & 8,20 & 25 \\
\hline Brinquedo com objeto natural & 3 & 2,33 & 15 \\
\hline $\begin{array}{l}\text { Brincadeira com brinquedo } \\
\text { eletrônico }\end{array}$ & 1 & 3,00 & 5 \\
\hline Brinquedo de faz-de-conta adulto & 1 & 1,00 & 5 \\
\hline
\end{tabular}

Tabela 4. Freqüência de crianças que apresentaram atividades de Observações de Contexto, percentagem do total da amostra e média de ocorrência da atividade por criança $(n=20)$

\begin{tabular}{|c|c|c|c|}
\hline Observação & $\begin{array}{l}\text { Total de } \\
\text { crianças }\end{array}$ & Média & Porcentagem \\
\hline $\begin{array}{l}\text { Observação de pessoa em } \\
\text { específico }\end{array}$ & 19 & 4,36 & 95 \\
\hline Observação de objeto específico & 17 & 2,70 & 85 \\
\hline Observação geral & 17 & 5,76 & 85 \\
\hline Observação de comida & 5 & 1,00 & 25 \\
\hline $\begin{array}{l}\text { Observação de estabelecimento } \\
\text { alimentício }\end{array}$ & 4 & 2,50 & 20 \\
\hline $\begin{array}{l}\text { Observação de objeto do mundo } \\
\text { adulto }\end{array}$ & 3 & 6,00 & 15 \\
\hline $\begin{array}{l}\text { Observação de programa infantil } \\
\text { na TV }\end{array}$ & 1 & 6,00 & 5 \\
\hline
\end{tabular}

Os dados da Tabela 4 demonstram que as crianças estão atentas para o movimento constante de pessoas nas ruas e que detém sua atenção em algumas delas, por questões específicas (situação sócio-econômica, tipo de vestimenta, etc.). Também há o interesse por produtos que são vendidos pelos camelôs, alimentos e programas nas TVs, que estão expostas em lojas de eletrodomésticos.

\section{Discussão}

Os dados deste estudo respondem a algumas questões relativas às atividades das crianças no seu cotidiano no ambiente da rua. Também, com o apoio da literatura na área e os pressupostos da Teoria dos Sistemas Ecológicos podem ser realizadas algumas inferências com relação ao processo proximal de desenvolvimento destas crianças e abrir espaço para a discussão de propostas de intervenção.

Inicialmente, os dados bio-sócio-demográficos e a própria composição da amostra devem ser discutidos. Neste estudo, a amostra foi composta por um grupo maior de me- 
ninos. Este dado é justificado em conjunto com a discussão de questões de gênero. Sabe-se que, em qualquer camada da população, existe um maior preparo dos homens para que eles ocupem espaços públicos. À mulher, inclusive por questões de proteção, é reservado o espaço privado da casa, onde ela aprende atividades de cuidado e manutenção deste lugar. No caso das crianças em situação de rua, este é um dado relevante, pois a rua é considerada um ambiente de alto risco e algumas famílias preferem se utilizar do trabalho das meninas dentro de casa, no cuidado com a roupa, louça e irmãos, incluindo neste processo questões importantes de sua socialização. Porém existe um outro lado nesta questão que merece ser mencionado. No mundo todo, a exploração sexual infanto-juvenil é constatada. No caso específico de crianças em situação de rua, esta atividade é relatada como forma de sobrevivência e envolve tanto meninos como meninas. Assim, a presença de mais meninas em situação de rua pode estar disfarçada em função da atividade realizada.

Com relação aos dados da entrevista estruturada, estes mostram que a grande maioria das crianças tem uma família, na qual ao menos um adulto é responsável pela sua subsistência. A presença das crianças na rua, trabalhando, aparece como um complemento da renda familiar. A casa da criança é um espaço de convivência de diferentes gerações (as crianças, os pais, os avós, os tios e os primos circulam freqüentemente neste espaço), caracterizando-se como um microssistema e um local de possíveis intervenções, na busca de melhoria da qualidade de vida de toda a família. As crianças que relataram morar nas ruas diferenciam das demais com relação à possível composição familiar e às possibilidades de recuperação do vínculo entre seus membros. Neste caso, é necessária uma avaliação dos riscos aos quais as crianças estavam expostas em suas famílias, sua motivação para permanecer nas ruas e as alternativas para esta situação. Em ambos os casos, a composição e atuação saudável do mesossistema são fatores determinantes para o sucesso das intervenções.

É relevante, também, analisar os dados relativos à escolarização das crianças. Sua defasagem escolar é nítida. A ausência prolongada destas crianças da escola afeta diretamente seu desenvolvimento sócio-emocional, perpetuando uma situação de marginalidade e falta de oportunidades. A escola pode ser o lugar da aprendizagem formal e o espaço de recuperação e implementação de aspectos evolutivos saudáveis, envolvendo a criança e sua família em uma rede de proteção e apoio, através da realização de atividades vinculadas aos processos proximais de desenvolvimento. Porém há um crescente desinteresse pela formação e reciclagem do conhecimento dos professores, há a falta de infra-estrutura e de apoio técnico, fatores ligados ao exossistema das crianças, provocando conseqüências graves e diretas para o seu desenvolvimento. A escola, enquanto microssistema, poderia criar oportunidades para que crianças, que se encontrem em risco para o desenvolvimento, possam ser acolhidas e tenham suas experiências de vida valorizadas. Outro aspecto a ser considerado na vinculação criança-famíliaescola é a inserção precoce da criança em atividades de tra- balho, que podem ser prejudiciais à sua freqüência escolar e à manutenção dos vínculos familiares.

Os dados de observação coletados neste estudo podem ser discutidos em diferentes níveis. Primeiramente, o estudo observacional possibilitou a composição de um pequeno quadro descritivo das atividades cotidianas destas crianças. É possível descrever parte de seu cotidiano, os contatos sociais estabelecidos e as oportunidades de interação com objetos e símbolos. A soma integrada e dinâmica destes aspectos reflete-se no desenvolvimento geral das crianças, na construção e significação de sua infância e nos seus projetos e expectativas para o futuro. Olhar para o processo proximal de desenvolvimento de crianças em situação de rua significa olhar para o seu desenvolvimento dentro deste microssistema específico, possibilitando analisar as variáveis possíveis e necessárias de modificação. Os dados sobre quem são seus pares de contato social mais freqüente e quais as atividades realizadas em conjunto demonstram isto. $\mathrm{O}$ adulto presente nas ruas seria um protetor e socializador em potencial, podendo implementar o desenvolvimento sócio-emocional das crianças, dentro de interações adequadas. Também, as atividades de cuidado com outros e os diálogos estabelecidos pelas crianças aparecem como alternativas para a introdução de valores e crenças fundamentais para o desenvolvimento, com a implementação dos valores morais, da competência social e de outras características pessoais e sociais de adaptação e proteção. Neste sentido, o papel que a criança desempenha nas atividades é, igualmente, relevante, pois se associa a características de autonomia e iniciativa, de proteção e conhecimento do ambiente.

Os dados de observação sobre as atividades motoras e de alimentação descrevem o espaço da rua como um ambiente que permite o exercício motor amplo, bem como a obtenção de meios para a subsistência alimentar. A movimentação no espaço da rua pode ser avaliada como a aprendizagem sobre o ambiente e suas potencialidades, valorizando a realização de atividades molares em determinados espaços e situações (as brincadeiras na praça, a alimentação na área dos restaurantes, as conversas com os camelôs, etc.).

A observação das atividades de brinquedo destaca a manutenção de algumas características tipicamente infantis e saudáveis, mesmo em um ambiente considerado como inadequado e hostil ao desenvolvimento. Os dados mostram o uso criativo de objetos que não são, usualmente, identificados como brinquedos, mas cuja presença no contexto estimula a criação e a realização de atividades lúdicas. O brincar nas ruas é uma atividade freqüente e deve ser entendida dentro do contexto em que ocorre. Este processo de contextualização permite a valorização das habilidades e conquistas da criança nos aspectos sócio-cognitivos envolvidos nestas atividades.

A atenção das crianças para as situações que acontecem à sua volta, explorando possibilidades de sobrevivência, cuidado e segurança, observadas no contexto da rua revela a dinâmica do funcionamento da rua. As crianças podem identificar pessoas importantes (possíveis “fregueses"), ou mesmo interessantes (que mostrem algo divertido, diferente, 
como roupas ou objetos de uso pessoal), além de aprender sobre situações de perigo ou de divertimento.

A análise integrada dos dados de observação e dos dados bio-sócio-demográficos revela o ambiente da rua como um microssistema real para as crianças que ali se encontram. É na rua, além de na família, vizinhança e outros ambientes, que elas estabelecem contatos sociais, que desempenham diferentes papéis e realizam diversas atividades. A observação naturalística das crianças neste contexto possibilita a identificação de componentes fundamentais ao seu processo de desenvolvimento proximal, delineado pelas atividades, pelos pares de contato social e pela continuidade temporal do é realizado. De uma maneira ampla, a criação deste quadro descritivo permite um olhar mais realístico para o desenvolvimento destas crianças. Não é mais adequado afirmar que são crianças que perderam sua infância, abandonadas e sobrevivendo pela prática de atos infracionais. Estas características possivelmente presentes no desenvolvimento em situação de rua, não são as únicas. A observação e a conversa com as crianças mostram uma paisagem mais complexa e multideterminada, com variáveis que envolvem deste o mesossistema das crianças, até questões macrossistemicas relativas aos valores, às crenças, aos planos econômicos e às formas de governo da sociedade na qual se inserem.

Finalizando, é necessário salientar a importância de estudos descritivos com populações de risco. As informações obtidas por meio destas pesquisas, quando analisadas dentro dos parâmetros da Teoria dos Sistemas Ecológicos, possibilitam uma visão mais ampla e real do fenômeno estudado, mesmo que isto implique explicações pela interação de muitas variáveis. A riqueza dos dados direciona propostas de intervenção, que devem privilegiar a intersecção de dados de observação e de atribuição de significado aos processos proximais de desenvolvimento das pessoas estudadas.

\section{Referências}

Alves, P. B. (1997). A ecologia do desenvolvimento humano: Experimentos naturais e planejados - Resenha. Psicologia, Reflexão e Crítica, 10(2), 369-373.

Alves, P. B. (1998). O brinquedo e as atividades de crianças em situação de rua. Dissertação de Mestrado não publicada. Programa de Pós-Graduação em Psicologia do Desenvolvimento da Universidade Federal do Rio Grande do Sul, Porto Alegre, RS.

Alves, P. B. (1999). Teoria dos sistemas ecológicos. Manuscrito não publicado. Programa de Pós-Graduação em Psicologia do Desenvolvimento da Universidade Federal do Rio Grande do Sul, Porto Alegre, RS.

Alves, P. B, Koller, S. H., Silva, A. S, Reppold, C. T., Santos, C. L., Bichinho, G. S., Prade, L. T., Silva, M. R. \& Tudge, J. (1999). A construção de uma metodologia observacional para o estudo de crianças em situação de rua: Criando um manual de codificação de atividades cotidianas. Estudos de Psicologia, 4(2), 289-309.

Alves, P. B., Koller, S. H. \& Tudge, J. (1996). Manual de codificação de atividades cotidianas de crianças em situação de rua. Ma- nuscrito não-publicado. Programa de Pós-Graduação em Psicologia do Desenvolvimento da Universidade Federal do Rio Grande do Sul. Porto Alegre, RS.

Aptekar, L. (1989). Characteristics of street children of Colômbia. Child Abuse and Neglect, 133, 427-437.

Aptekar, L. (1994). Street children in the developing world: A review of their condition. Cross Cultural Research, 28, 195-224.

Bandeira, D. R., Koller, S. H., Hutz, C. S. \& Forster, L. (1994, Outubro). O cotidiano de meninos e meninas de rua. Trabalho apresentado no XVII International School Psychology Colloquium. Campinas, SP.

Bemak, F. (1996). Street researchers: A new paradigm redefining future research with street childrem. Childhood, 3, 147-156.

Bronfenbrenner, U. (1989). Ecological systems theory. Annals of Child Development, 6,187-249.

Bronfenbrenner, U. (1993). The ecology of cognitive development: Research models and fugitive findings. Em R. Wozniak \& K. Fischer (Orgs.), Development in context: Acting and thinking in specific environments (pp. 3-44). Hillsdale, NJ: Erlbaum.

Bronfenbrenner, U. (1995). Developmental ecology through space and time: A future perspective. Em P. Moen, G.H. Elder \& K. Lüscher (Orgs.), Examining lives in context - Perspectives on the ecology of human development (pp.619-648). Washington: American Psychological Association.

Bronfenbrenner, U. (1996). A ecologia do desenvolvimento humano: Experimentos naturais e planejados. Porto Alegre: Artes Médicas. (Original publicado em 1979).

Bronfenbrenner, U. \& Morris, P. (1998). The ecology of developmental processes. Em W. Damon (Org.), Handbook of child psychology (Vol. 1, pp.993-1027). New York: John Wiley \& Sons.

Carraher, T. N., Carraher, D. W. \& Schliemann, A. D. (1985). Mathematics in the street and in the schools. British Journal of Developmental Psychology, 3, 21-29.

Cecconello, A.L. (1999). Competência social, empatia e representação mental da relação de apego em famílias em situação de risco. Dissertação de Mestrado não publicada. Programa de Pós-Graduação em Psicologia do Desenvolvimento da Universidade Federal do Rio Grande do Sul. Porto Alegre, RS.

Connoly, M. \& Ennew, J. (1996). Children out of place. Childhood, 3, 131-145.

Forster, L. M. K., Barros, H.M.T., Tannhauser, S.L. \& Tannhauser, M. (1992). Meninos na rua: Relação entre abuso de drogas e atividades ilícitas. Revista da ABP-APAL, 14, 115-120.

Garmezy, N. \& Masten, A (1994). Chronic adversities. Em M. Rutter, E. Taylor \& L. Herson (Orgs.), Child and adolescent psychiatry (pp. 191-207). Oxford: Blackwell.

Hutz, C.S. \& Koller, S.H. (1997). Questões sobre o desenvolvimento de crianças em situação de rua. Estudos em Psicologia, 2, 175-197.

Hutz, C.S. \& Koller, S.H. (1999). Methodological and ethical issues in research with street children. Em M. Raffaelli, \& R. W. Larson (Orgs.), Homeless and working youth around the world: Exploring developmental issues. New Directions for Child and Adolescent Development, 85, 59-70.

Koller, S.H. (1994). Julgamento moral pró-social de meninos e meninas de rua. Tese de Doutorado não publicada. Curso de 


\section{Crianças em situação de rua}

Pós-Graduação em Educação, Pontifícia Universidade Católica do Rio Grande do Sul. Porto Alegre, RS.

Kuschick, M., Reppold, C., Dani, D., Raffaelli, M. \& Koller, S. H. (1996, Outubro). A visão dos meninos de rua sobre sua situação de vida. Trabalho apresentado na XXVI Reunião Anual da Sociedade Brasileira de Psicologia. Ribeirão Preto, SP: SBP.

LaCharité, C. (1998). Abuso e negligência na infância e adolescência. Manuscrito não publicado. Curso de Pós-Graduação em Psicologia do Desenvolvimento da Universidade Federal do Rio Grande do Sul. Porto Alegre, RS.

Mayer, L.R. (1998). Controle percebido e desempenho acadêmico de crianças de nível sócio-econômico baixo. Dissertação de Mestrado não-publicada. Programa de Pós-Graduação em Psicologia do Desenvolvimento da Universidade Federal do Rio Grande do Sul. Porto Alegre, RS.

Nunes, T. (1994). O ambiente da criança. Cadernos de Pesquisa, $89,5-23$.

Peres, V.L.A. (1997). Família de crianças em situação de rua: Modos de vida, relacionamento familiar e práticas educativas.
Dissertação de Mestrado não publicada. Faculdade de Educação, Universidade Federal de Goiás. Goiânia, GO.

Reppold, C., Santos, C.L., Silva, A.S., Silva, M.R., Alves, P.B. \& Koller, S.H. (1996a, Outubro). Brinquedo, brincadeira e crianças em situação de rua: Um estudo em Porto Alegre. Trabalho apresentado na XXVI Reunião Anual da Sociedade Brasileira de Psicologia. Ribeirão Preto, SP: SBP.

Reppold, C., Santos, C.L., Silva, A.S., Silva M.R., Alves, P.B. \& Koller, S.H. (1996b, Outubro). O cotidiano e a rua: Atividades de crianças em situação de rua na cidade de Porto Alegre. Trabalho apresentado na XXVI Reunião Anual da Sociedade Brasileira de Psicologia, Ribeirão Preto, SP: SBP.

Rutter, M. (1993). Resilience: Some conceptual considerations. Journal of Adolescent Health, 14, 626-631.

Tudge, J., Sidden, J., \& Putnam, S. (1994). The cultural ecology of young children: Coding manual. Manuscrito não publicado. University of North Carolina at Greensboro.

Zeebell, C.R., Garcia, M.L. \& Silveira, D.M. (1995). O que sabem os meninos e meninas de rua. Mundo da Rua, 1, 3-20. 